\title{
Ação docente no Ensino Superior: indicativos da articulação teoria e prática
}

\section{Teaching action in Higher Education: indicative of articulation theory and}

\author{
practice
}

\author{
, Camila Lima Coimbra *, Helena Maria dos Santos Felício ** \\ *Universidade Federal de Uberlândia, **Universidade Federal de Alfenas
}

\begin{abstract}
Resumo
No processo de construção da ação docente, a articulação entre a teoria e a prática tem sido apresentada como um dos principais aspectos favorecedores de uma prática pedagógica de qualidade que envolve o processo de ensinar e o processo de aprender. Desta forma, esta articulação, emergiu da fala de sujeitos, professores do Ensino Superior, que se dispuseram a participar de nossa pesquisa, que discute a qualidade da ação docente no Ensino Superior. Neste sentido, o objetivo deste trabalho pressupõe evidenciar as concepções que traduzem uma prática docente de qualidade desvelada por meio da articulação entre teoria e prática.

Palavras chave: formação de professores, teoria e prática, Ensino Superior.
\end{abstract}

\begin{abstract}
In the process of construction of teaching action, the articulation between theory and practice has been presented as one of the main aspects favoring a quality pedagogical practice that involves the process of teaching and the process of learning. In this way, this articulation emerged from the speech of subjects, Higher Education teachers, who were willing to participate in our research, which discusses the quality of teaching action in Higher Education. In this sense, the objective of this work presupposes to highlight the conceptions that translate a teaching practice of quality unveiled through the articulation between theory and practice.

Keywords: teacher training, theory and practice, Higher Education.
\end{abstract}

\section{Introdução}

Nos relatos de ações e impressões do exercício da docência, em diversos cursos do Ensino Superior, foi possível identificar vários fragmentos que apontam uma prática docente considerada de qualidade a partir do momento em que conseguem relacionar a teoria e a prática.

Essa relação apresenta-se de diversas formas, com diferentes configurações. Neste sentido, o objetivo deste artigo é, ao registrar as falas dos sujeitos, evidenciar as concepções que traduzem uma prática docente de qualidade desvelada por meio da articulação entre teoria e prática.

Frente às exigências do mundo do trabalho, o "saber" e o "saber fazer" são elementos indissociáveis que, na afïmação de Sacristán (1999), movem a ação educativa na perspectiva de proporcionar-lhe um trânsito cuja ação desejada se constitua entre o pensamento e a atividade, entre o mundo da teoria e o mundo da prática.

Dentre os autores que abordam a questão da relação teoria-prática, Candau e Lelis (1989) descrevem dois esquemas - a visão dicotômica e a visão de unidade para a compreensão dessa relação, como dimensões que explicam a realidade e que determinam a prática pedagógica dos educadores.

Essa visão dicotômica associativa da relação teoria-prática é, também, denunciada por Tardif (2002). Para o autor, a supremacia de um sobre o outro gera, na verdade, a desvalorização de um dos dois elementos que, em geral é o da prática, e não a tentativa de unidade.

No dizer de Canário (2001), esse modelo dicotômico aplicacionista da relação teoria-prática prevaleceu, durante tempos no processo da formação profissional, a ponto de separar, também, os espaços/tempos destinados à formação e os espaços/tempos destinados à aplicação da teoria aprendida. Contudo, esse modelo não responde mais às necessidades da realidade, uma vez que "a mais importante mutação registrada no campo da formação profissional é a passagem de uma relação de possibilidade em relação ao mundo do trabalho, para outro tipo de relação marcada pela incerteza". (Canário, 2001, p. 34).

O fim das certezas no campo profissional sobretudo pela rapidez com que os conhecimentos se tornam obsoletos e as mudanças das condições de trabalho provenientes de questões tecnológicas, culturais, sociais, humanas - faz com que a situação de aplicabilidade, de adequação e adaptação dos conhecimentos não responda mais às necessidades emergentes na relação atual entre a formação e o trabalho. Se, em outras épocas, a possibilidade de aplicações, de adequações e adaptações dos conhecimentos era real, hoje é diferente.

Embora ainda encontremos práticas pedagógicas como essa, elas são cada vez mais questionadas por não responderem às necessidades atuais, uma vez que os tempos são outros, as referências sociais são outras, os conhecimentos são outros, as relações interpessoais são outras. A incerteza, a relatividade, a mobilidade são as novas características do conhecimento, da atuação profissional e do campo de trabalho nessas últimas décadas. 
$\mathrm{Na}$ visão da unidade, Candau e Lelis (1989) descrevem que existe uma vinculação, uma união entre a teoria e a prática. Contudo, essa "unidade não significa identidade entre esses dois pólos. Há uma distinção entre teoria e prática no seio de uma unidade indissociável, assegurada pela relação simultânea e recíproca, de autonomia e dependência de uma em relação à outra". (Candau \& Lelis, 1989, p. 54).

Segundo as autoras, é justamente na compreensão desse movimento de autonomia e dependência, de simultaneidade e reciprocidade, entre a teoria e prática, apesar de suas especificidades, que é possível perceber a dimensão indissociável dessa relação que é definida como práxis por se manifestar como "atividade teórico-prática", ou seja, na mesma atividade, co-existem as dimensões teórica e prática da realidade, superando a visão dicotômica da relação existente entre a teoria e a prática.

É nessa visão de unidade entre a teoria e prática, entre o saber e trabalho, que a formação profissional se instaura na possibilidade de edificar a sua identidade a partir de um movimento de alternância que se constrói "em simultâneo com os conhecimentos teóricos e com os saber da ação" (MALGLAIVE, 1997, p. 57).

\section{Os sujeitos definem a teoria e prática em uma ação docente de qualidade}

Ao trabalharmos com os fragmentos indicativos da articulação teoria e prática, das falas dos sujeitos, professores universitários, pudemos identificar diversas formas que evidenciam a compreensão de tal articulação, ora em um conceito uno, ora em um conceito diverso, ora como fonte de luz, ora como um abismo. Desta forma, o exercício de organizarmos em subcategorias apresenta-se nesta construção textual como forma didática que encontramos para abordar o tema trabalhado.

\section{a) Tematização da Prática}

A articulação entre a teoria e a prática, entendida como "tematização da prática" é uma das compreensões identificadas nos relatos dos professores.

Segundo Weisz (2000), a "tematização da prática" realizada em sala de aula é entendida como o movimento constante de reflexão - ação - refexão, que permite transitar pela teoria e pela prática sem provocar a fragmentação destes dois elementos considerados fundamentais no processo formativo, bem como construir aprendizagens sobre o objeto de ensino e sobre as condições didáticas necessárias para que os educandos se apropriem dos conteúdos, como podemos identificar no seguinte relato:

"(...)Em pequenos grupos os educandos pesquisaram brincadeiras em diferentes estados da federação, fortalecendo a concepção da brincadeira como elemento cultural. Por fim, tematizamos rotinas reais de organização do tempo $e$ do espaço em instituições de educação infantil $e$ os educandos inseriram a brincadeira como estruturante do cotidiano infantil, em diversas faixas etárias, culminando com o exercício do brincar".

"Um exemplo bom é quando os alunos dos anos mais avançados começam a "por a mão na massa", com estudos de caso que se tornam desafiadores para eles. Aí a motivação é enorme e tudo flui prazerosamente".

"Na disciplina de Gestão Social, no $7^{\circ}$ período, as alunas desenvolvem um Planejamento Estratégico. Elas escolhem o objeto, identificam a missão, valores e princípios, traçam objetivos $e$ metas, apresentam alternativas para intervenção. Verifico a qualidade da atividade porque já colocaram em prática”.

"Considero importante que os alunos tirem suas próprias conclusões da observação prática e depois possam confrontar os resultados com as teorias desenvolvidas sobre os temas abordados".

Fazer o exercício, exercitar, "colocar a mão na massa" são formas de compreensão do espaço e lugar da prática, como registrado nessas falas dos sujeitos. Diante desse cenário, Veiga (1989) apresenta duas possibilidades de direção da prática pedagógica, a repetitiva e a reflexiva. A primeira constitui-se por uma atividade prática, baseada em uma visão utilitarista, ativista e espontaneísta, em que a fragmentação do conhecimento encontra espaço para se efetivar, e a inserção do novo, dificuldade para se estabelecer. Já a prática pedagógica reflexiva tem [...] como pontos de partida e chegada a prática social. Caracteriza-se pela indissolubilidade entre teoria e prática, em que as dicotomias tendem a desaparecer" (Schmidt; Ribas \& Carvalho, 2003, p. 23).

Essa busca da prática pedagógica reflexiva, que insiste em um processo inquietante de desenvolver as habilidades para o questionamento, a crítica e a reflexão sobre o contexto e as ações praticadas estão na busca da coerência entre o conceito/concepção e a ação realizada. "A prática pedagógica, nesse contexto, caracteriza-se como fonte de conhecimento e geradora de novos conhecimentos. Nessa perspectiva, o novo encontra aqui o nicho ideal para vicejar e expandir-se" (Schmidt; Ribas \& Carvalho, 2003, p. 23).

Assim, pensar em prática significa, necessariamente, pensar em teoria, falar da prática dissociada de sua relação com a teoria seria incorrer em equívocos históricos em que a prática foi vista como imitação de modelos ou mesmo uma instrumentalização técnica. Para entendermos desse modo, talvez a melhor forma de denominá-la seja práxis educativa (Sacristán, 1999).

\section{b) Professor-Reflexivo e Professor-Investigador}

A articulação entre teoria e prática também aparece em um movimento de reflexão que o professor faz sobre sua prática em sala de aula, inserindo-o assim na categoria de Professor-Reflexivo, cuja adjetivação surge com Schön (1995) para tratar justamente da forma como os profissionais atuam em ações e atividades a partir de seu conhecimento profissional, bem como dos processos de mudança na formação do mesmo.

Schön (1995) propõe três processos e conceitos que devem compor a prática de um professor-reflexivo: o conhecimento na ação "é o componente inteligente que orienta toda a atividade humana, manifesta-se no saber fazer" (Gómez, 1998, p. 369), a reflexão na ação "é fácil reconhecer como na vida cotidiana frequentemente pensamos sobre o que fazemos ao mesmo tempo que agimos" (Gómez, 1998, p. 370) e, finalmente, a reflexão sobre a ação e sobre a reflexão na ação "pode ser considerada como a análise a posteriori sobre as características e processos de sua própria ação" (Gómez, 1998, p. 371).

$\mathrm{O}$ relato seguinte indica estes três processos desenvolvidos pelo professor que ao analisar sua prática, os pressupostos da disciplina que leciona, o que os alunos, culturalmente esperam em tal disciplina, constata que a ação pedagógica no interior de uma determinada disciplina deve estar para além daquilo que é muitas vezes esperado pelos alunos, e este indicativo pode incidir na qualidade da ação docente.

"Porque a minha disciplina é Didática - uma disciplina que tem a ver com a prática. Aí, corre-se 
o risco grande, porque em geral, a didática é significativa sob a perspectiva da prática. A gente precisa o tempo todo entender que a didática é mais do que oferecer um rol de técnicas de ensino, de método de ensino. (...) Então, isso, às vezes, me coloca em dúvida se o meu trabalho é de qualidade".

"As aulas são preparadas de acordo com o previsto para o ano/semestre e, adequadas ao nível da turma, isto é, de forma que todos apreendam o conteúdo e sua aplicabilidade. No decorrer do ano, pautado no subsídio teórico e nas oficinas, os universitários percebem que teoria e prática são indissociáveis".

De acordo com este relato, é possível constatar que o professor reflexivo entende o seu papel a partir das diferentes situações vivenciadas e entende a sua efetiva contribuição para agir sobre ela. Na análise de Contreras (2002, p. 111) sobre o pensamento de Schön, "a prática é em si um modo de pesquisar, de experimentar com a situação para elaborar novas compreensões adequadas ao caso, ao mesmo tempo em que se dá a transformação da situação".

O relato apresentado também se insere na metáfora de professor-investigador que, de acordo com Sacristán (2002), foi criada por Stenhouse (1984). Para o professor investigador de Stenhouse, o ensino é uma arte, pois significa a expressão de determinados valores e princípios que se realizam na própria prática de ensino. Compara os docentes com os artistas que melhoram sua arte experimentando-a, examinando-a criticamente. Estabelece um paralelo entre o professor e o músico que tenta extrair o que há de mais valioso em uma partitura, pesquisando possibilidades, examinando efeitos, até encontrar o que para ele expressa seu autêntico sentido musical. $\mathrm{O}$ mesmo sentimento, criatividade, vivacidade que rege um artista deve, da mesma forma, reger o professor.

Nessa concepção de professor investigador, o exercício docente é configurado como um hábito em que o professor é compreendido como pesquisador de sua própria prática. "A docência pode, em grande medida, ser um hábito, uma construção pessoal de habilidades e recursos com os quais resolvemos nossa prática, mas que em determinados momentos somos capazes de torná-la consciente para poder aperfeiçoá-la" (Contreras, 2002, p. 118).

\section{c) $O$ exercício da pesquisa}

Outro aspecto identificado nos relatos, diz respeito ao exercício da pesquisa como percurso metodológico para a articulação entre a teoria e a prática.

Esteban e Zaccur (2002) afirmam que é na inserção cotidiana em diferentes espaços e contextos que surgem questões que alimentam a necessidade de saber mais, indicando, desta forma, que a pesquisa, como recurso metodológico, apresenta formas concretas de articulação, tendo a prática como ponto de partida e como finalidade, sem que isso signifique a supremacia da prática sobre a teoria. Como podemos verificar nos relatos seguintes:

"(...) O retorno é sempre muito produtivo e fica mais fácil para eles entenderem a teoria depois que vão ao campo".

"As oficinas de alfabetização. Durante estas atividades, os alunos relacionam a teoria à possibilidade de criação em uma ação alfabetizadora".

“(...)Tem qualidade ainda, por que procuro fazer com que os alunos brinquem, riam, façam associações com situações cotidianas ou familiares, com isso além de compreender eles apreendem o conteúdo (...)".

A compreensão de que a prática é o contexto do questionamento, do levantamento de dúvidas, contribuiu para avançarmos na premissa de que o contexto da prática é, ao mesmo tempo, objeto deste questionamento teórico, bem como fonte para a formulação de novos conhecimentos, transformando-se, assim, em práxis, ou seja, na síntese teoriaprática.

$\mathrm{Da}$ mesma forma, os relatos apresentados anteriormente, nos remetem à indissociabilidade entre 0 ensino com a pesquisa, indicado Freire (1996, p. 29) quando afirma que um não existe sem o outro, sobretudo porque "enquanto ensino, continuo buscando, reprocurando. [...] Pesquiso para constatar, constatando, intervenho, intervindo educo e me educo".

Desta forma, quando a pesquisa é utilizada como recurso metodológico para a articulação entre a teoria e a prática, é possível evidenciar que o conhecimento se constrói de forma mais significativa para os alunos.

\section{d) Aplicação da teoria na prática}

É possível identificar, também, nos relatos dos professores que a articulação entre a teoria e a prática se dá pela aplicação da primeira na segunda. Esta é uma concepção que se fundamenta nas orientações técnicas da formação profissional e pressupõe que o ensino é uma ciência aplicada, que existe um conhecimento profissional básico e, posteriormente, um espaço para aplicação eficiente do conhecimento.

Segundo Freire (2001), esta concepção pressupõe que existe um conhecimento para a prática, pronto a ser usado, subentendendo que conhecer mais conduz a uma prática com maior qualidade. É o que podemos perceber nos relatos seguintes:

“(...) Como no exemplo anterior, porque a teoria transformada em prática, estimula mais o aprendizado, a atenção e o interesse do aluno".

"Aulas divididas em partes, de modo que na primeira parte os alunos tenham a preparação/capacitação teórica e na segunda parte, eles possam aplicar os conceitos/conhecimentos adquiridos em uma atividade prática, como uma discussão de um estudo de caso ou uma pesquisa direcionada."

"Costumo dar a teoria e depois passar o filme para o aluno relacionar a teoria e realidade, verificar a aplicação do conteúdo”.

"O que faço, é a partir do plano da aula, dou os objetivos da disciplina e em seguida já dou uma coisa prática. Toda aula tem daquilo que foi falado uma coisa prática”.

"Então eu sempre faço, (...) eu sempre procuro ter deles um retorno de como é que eles vão aplicar esse conteúdo visto na sua prática diária se não, não faz sentido, (...)”.

"Tem qualidade por que enfoco questões $e$ conceitos que os alunos conseguem aplicar na prática”.

"Como no exemplo anterior, porque a teoria transformada em prática, estimula mais o aprendizado, a atenção e o interesse do aluno".

"Eu entendo que temos que despertar no aluno o interesse em aprender, mostrando a importância e a aplicação prática do que está sendo passado para ele".

"Bem.... Eu acho importante em sala de aula fazer o aluno participar, (...)sempre mostrando ao aluno a aplicação prática da matéria em sua vida/carreira". 
É possível perceber que, ao assumir a relação entre a teoria e prática a partir desta concepção aplicacionista, os professores interpretam estas preocupações procurando aumentar o conhecimento disciplinar.

Neste sentido, ainda segundo Freire (2001), o uso de práticas reflexivas são utilizadas, apenas, com finalidades de interpretação das situações vivenciadas que, em geral realizam julgamentos dos saberes profissionais que são reorganizados de acordo com a experiência pessoal.

Deste modo, entender a relação entre teoria e prática como a aplicação da primeira sobre a segunda, entende o desenvolvimento profissional como "aquisição" de uma competência que acaba sendo valorizada somente na prática.

\section{e) Dimensão interdisciplinar/integradora}

Visualiza-se, assim, as falas dos sujeitos como espaço de contradição e mudança, quando algo que se pretende inovador é lançado em um ambiente caracterizado por seu "encruamento". Inovador, pois desata as amarras disciplinares à medida que pressupõe outra lógica de organização, não linear, espiralada em que as realidade e a teoria gravitam em seu entorno. Inovador, também, por exigir formas de organização que não se enquadram em um modelo de organização curricular tradicional.

Pode-se compreender essa articulação teoria e prática como uma possibilidade de resistência à disciplinarização/especialização na formação inicial. Ou seja, as falas dos sujeitos demonstram a integração dos conteúdos como algo realizado em uma perspectiva da prática de qualidade. Utilizando Sacristán (1999), podemos identificar essa integração como um exemplo para tentar dar resposta à necessidade de integrar o conhecimento e a cultura.

A partir de um projeto de flexibilização curricular em que o eixo seja a teoria e a prática, funcionando como articulador dos conteúdos de um curso, tendo como olhar a realidade, algo bem próximo e interessante dos alunos e professores. Os projetos, nesta linha, trabalham temas e problemas que podem atuar como centros de interesses e, ao mesmo tempo, a elaboração de projetos de ensino, pesquisa e extensão, relacionam diferentes competências e múltiplas fontes de informação.

“(...) Quando eu penso em uma atividade de qualidade é aquela que traga indicativos que eles estão interessados e que esse interesse pode proporcionar um conhecimento, um produto final".

"A experiência mais relevante que vivenciei, foi no Projeto Integrado de Prática Educativa (PIPE III) em que foi possível desenvolver um trabalho integrado com os colegas de um mesmo período".

"Na minha opinião, relacionar a teoria com a realidade do aluno tem qualidade requerida ao processo ensino aprendizagem".

"E tenho ainda uma prática em que o discente é associado constantemente nas discussões propostas.".

"As atividades práticas realizadas em conjunto com a exposição teórica facilitam o desenvolvimento do correto procedimento manual e facilitam a interiorização e melhor entendimento do conhecimento teórico".

"Acredito que a discussão do texto clássico a partir de um elemento da realidade cotidiana, devidamente contextualizada, ajude o educando a estabelecer os pontos necessários para assimilar o conhecimento e, mais que isso, colocá-lo em prática $e$, não apenas, saber que ele existe".

"Porque levo para sala de aula a preparação de uma aula teórico/prática e procuro sempre demonstrar a prática pela minha vivência no setor empresarial privado que também atuo".

Em Sacristán (2000) existe uma contribuição de Grundy (1987) sobre os princípios que contribuem para um currículo com interesse emancipatório, entendido como uma práxis. O primeiro princípio entende que "deve ser uma prática sustentada pela reflexão enquanto práxis" (p. 48), pois se constrói por meio de uma interação entre o refletir e o atuar, dentro de um processo circular que compreende o planejamento, a ação, a avaliação, integrado em uma lógica espiral. O segundo princípio revela que "uma vez que a práxis tem lugar num mundo real e não em outro" (p. 48) não deveria ser separado das condições concretas de realização. Já o terceiro princípio declara que "a práxis opera num mundo de interações, que é o mundo social e cultural", (p. 48) com isso, não podemos nos referir exclusivamente aos problemas de aprendizagem, sem percebê-los como atos sociais dentro de determinadas condições. O quarto princípio em que define "o mundo da práxis é um mundo construído, não natural" (p. 49), o currículo torna-se uma construção social, portanto, é necessário compreender a rede complexa que estabelece suas relações entre o interinstitucional e o extrainstitucional. E, por fim, o quinto princípio, em que "a práxis assume o processo de criação de significado como construção social, não carente de conflitos, pois se descobre que esse significado acaba sendo imposto pelo que tem mais poder de controlar o currículo" (p. 49)

\section{Considerações Finais}

Ao buscar, neste texto, as bases epistemológicas das falas dos sujeitos em seus lugares e espaços educativos, desvelando conceitos e definições que sustentam suas reflexões, análises e interpretações sobre a articulação teoria e prática na docência universitária, somos levadas a concordar com a manifestação de um dos sujeitos quando declara que "a relação entre a teoria e a prática no ensino superior é mal resolvida".

É interessante perceber que tal situação manifesta-se de diversas maneiras, nos diferentes significados atribuídos pelos professores à relação entre teoria e prática no Ensino Superior.

Entendemos que o grande desafio instalado na relação teoria e prática, sobretudo no Ensino Superior, é a necessidade de avançarmos na compreensão desta relação a partir de um paradigma que "ultrapasse a visão uniforme e linear e que desencadeie uma visão de rede, de teia, de interdependência" (Behrens, 2005, p. 111) de saberes teóricopráticos, tão necessários a qualquer processo formativo.

São princípios da abordagem do ensino com pesquisa, de acordo com Behrens (2005): enfocar o conhecimento; valorizar a ação reflexiva, estimular a análise, valorizar a ação, a reflexão crítica; exercitar o pensamento divergente, compreender o conhecimento de forma interdisciplinar, e, por fim, conceber a pesquisa como atividade inerente ao ser humano.

Esses princípios gravitam em torno desses saberes teóricopráticos que exigem uma reflexão crítica permanente por meio dos docentes universitários. Essa pesquisa conseguiu identificar as formas/configurações nas quais incorporamos essa relação em nossas práticas em sala de aula, quando as consideramos de qualidade.

Um bom começo, pois o eixo para essa reflexão parte de um enfoque que busque a realidade como ponto de partida de nossa ação docente, seja em um contexto educativo ou uma situação didática presentes. Talvez a grande dificuldade da ação docente esteja nessa referência para o ponto de partida, pois trazer esse ponto 
de partida para o espaço da sala de aula exige do docente ir além do conhecimento propriamente dito. Romper as barreiras do conhecimento fragmentado e reconhecer a necessidade de uma visão integrada ou integradora nas diversas áreas do conhecimento. $\mathrm{O}$ registro de um bom começo associa-se a um ponto de partida para a reflexão de nossa ação docente por meio da reflexão realizada nesse artigo. Partimos da fala dos sujeitos para indicarmos a reflexão sobre a relação teoria e prática. Partimos dessa realidade...

\section{Referências}

Behrens, M. A. (2005). O Paradigma Emergente e a Prática Pedagógica. Petrópolis, RJ: Editora Vozes.

Canário, R. (2001). A prática profissional na formação de professores. IN: CAMPOS, B. P. (org.). Formação Profissional de Professores no Ensino Superior. Porto: Porto Editora. p. $31-45$.

Candau, V. M. \& Lelis, I. A. (1989). A relação teoria-prática na formação do educador. In: V. M. Candau (org.). Rumo a uma nova didática. 2 ed. Petrópolis, RJ: Vozes. pp. $49-63$.

Contreras, J. (2002). A autonomia dos professores. São Paulo: Cortez.

Esteban, T. \& Zaccur, E. (Org.). (2002). Professora-pesquisadora: uma práxis em construção. Rio de Janeiro: DP\&A.

Freire, P. (1996). Pedagogia da Autonomia: saberes necessários à prática educativa. São Paulo: Paz e Terra.

Freire, A. M. (2001). Concepções Orientadoras do Processo de Aprendizagem do Ensino nos Estágios Pedagógicos. Colóquio: Modelos e Práticas de formação Inicial de Professores, Faculdade de Psicologia e de Ciências da Educação, Universidade de Lisboa. Lisboa, Portugal.

Gómez, A. I. P. (1998). A função e formação do professor/a no ensino para a compreensão: diferentes perspectivas. In: J. G. Sacristán, J. Gimeno \& A. I. P. Gómez. Compreender e transformar o ensino. 4. ed. Porto Alegre: Artmed.

Malglaive, G. (1997). Formação e Saberes Profissionais: Entre a Teoria e a Prática. IN: R. Canário (org.). Formação e Situações de Trabalho. Porto: Porto Editora.

Sacristán, J. G. (2002). Educar e conviver na cultura Global: as exigências da cidadania. Porto Alegre, RS: Porto Alegre, RS: Artmed.

Sacristán, J. G. (2000). O currículo: uma reflexão sobre a prática. 3 ed. Porto Alegre, RS: Porto Alegre, RS: Artmed.

Sacristán, J. G. (1999). Poderes Instáveis em Educação. Porto Alegre, RS: Porto Alegre, RS: Artes Médicas do Sul.

Schmidt, L. M.; Ribas, M. H. \& Carvalho, M. A. (2003). A prática pedagógica como fonte de conhecimento. In: M. Alonso \& A. G. Queluz (Org.). $\mathrm{O}$ trabalho docente: teoria e prática. São Paulo: Pioneira Thomson Learning.

Schön, D. (1995). Formar professores como profissionais reflexivos. In: A. Nóvoa (Coord.). Os professores e sua formação. Lisboa: Dom Quixote.
Tardif, M. (2002). Saberes Docentes e Formação Profissional. 2 ed. Petrópolis, RJ: Vozes.

Weisz, Telma. (2000). O diálogo entre o ensino e a aprendizagem. São Paulo: Ática. 